arm protonated. The relatively long time scale for the onset of dissociation of one arm of the tpen ligand in acidic media as compared to the NMR experiment rules out the possibility of a dissociative enantiomerization process.

Conclusions. [ $\mathrm{Fe}($ tpen $)]\left(\mathrm{ClO}_{4}\right)_{2},{ }^{2} /{ }_{3} \mathrm{H}_{2} \mathrm{O}$ undergoes a spincrossover transformation with $T_{\mathrm{c}}=365 \mathrm{~K}$ in the solid state and $T_{\mathrm{c}}=363 \mathrm{~K}$ in a DMF solution. This is the first $\mathrm{Fe}^{\mathrm{II}}$ spin-crossover complex to have a spin-state interconversion rate in the solid state which is faster than can be sensed by ${ }^{57} \mathrm{Fe}$ Mössbauer spectroscopy. The absence of intermolecular interactions, i.e., a simple spinequilibrium for each [Fe(tpen) ${ }^{2+}$ complex, has been demonstrated by, inter alia, dilution studies with the isostructural $\mathrm{Zn}^{2+}$ complex. The results of X-ray structure determinations at 298 and $358 \mathrm{~K}$ show that the $[\mathrm{Fe}(\mathrm{tpen})]^{2+}$ complex has an appreciable trigonal twist up and beyond what is expected for an octahedral complex. Furthermore, this trigonal twist increases as the amount of high-spin content increases. It is suggested that the trigonal twist in [Fe(tpen)] ${ }^{2+}$ leads to an increased spin-orbit interaction between
${ }^{1} A_{1}$ and ${ }^{5} T_{2}$ states as a result of decreasing the energy of intermediate triplet states. This then results in an increased rate of spin-state interconversion. In solution $[\mathrm{Fe}(\mathrm{tpen})]^{2+}$ exhibits a relatively fast rate of enantiomerization which supports the idea that a trigonal twisting motion is coupled to the spin-state interconversion process.

Acknowledgment. We are grateful for funding from National Institutes of Health Grant HL13652 (D.N.H.).

Supplementary Material Available: Tables of anisotropic thermal parameters for [ $\mathrm{Fe}(\mathrm{tpen})]\left(\mathrm{ClO}_{4}\right)_{2}$ at $298 \mathrm{~K}$ and $[\mathrm{Fe}$ (tpen)] $\left(\mathrm{ClO}_{4}\right)_{2}{ }^{2} /{ }_{3} \mathrm{H}_{2} \mathrm{O}$ at 298 and $358 \mathrm{~K}$, as well as chemical analysis, ${ }^{57} \mathrm{Fe}$ Mössbauer, and magnetic susceptibility data and figures showing Mössbauer spectra, magnetic moment vs temperature plots, and temperature dependence of the $60-\mathrm{MHz}{ }^{1} \mathrm{H}$ NMR spectrum of $[\mathrm{Fe}$ (tpen) $] \mathrm{I}_{2}$ in $1: 1 \mathrm{MeOH} / \mathrm{H}_{2} \mathrm{O}$ (31 pages); listing of observed and calculated structure factors (36 pages). Ordering information is given on any current masthead page.

\title{
Three Paramagnetic Reduction Stages of Phenyl-Substituted 1,2:9,10-Dibenzo[2.2]paracyclophane-1,9-dienes. Radical Anions, Triplet Dianions, and Radical Trianions As Studied by ESR and ENDOR Spectroscopy ${ }^{1}$
}

\author{
Armin de Meijere, ${ }^{\dagger, \delta}$ Fabian Gerson, ${ }^{* . \downarrow}$ Burkhard König, ${ }^{\dagger}$ Oliver Reiser, ${ }^{\dagger}$ and \\ Thomas Wellauer \\ Contribution from the Institut für Physikalische Chemie der Universität Basel, \\ Klingelbergstrasse 80, CH-4056 Basel, Switzerland, and Institut für Organische Chemie der \\ Universität Hamburg, Martin-Luther-King-Platz 6, D-2000 Hamburg 13, F.R.G. \\ Received March 26, 1990
}

\begin{abstract}
Reduction of di- and tetraphenyl-substituted 1,2:9,10-dibenzo[2.2]paracyclophane-1,9-dienes, 3, 3- $d_{2}, 4,5$, and 5-t $\mathrm{Bu}_{4}$ with potassium in ethereal solvents has been monitored by ESR and ENDOR spectroscopy. In each case, the first reduction step yields a radical anion in which the unpaired electron resides in one of the two lateral biphenyl or $a$-terphenyl $\pi$-systems orthogonal to the central phane unit. Except under conditions of strong association with the $\mathrm{K}^{+}$counterion, electron exchange between the two $\pi$-systems is fast on the hyperfine time scale. Upon further reduction, a second electron is taken up, as revealed by the appearance of triplet dianions bearing one unpaired electron in each of the two lateral $\pi$-systems (separation ca. $1 \mathrm{~nm}$ ). The singlet state of the dianion of 5 has been estimated to lie only slightly higher (ca. $2 \mathrm{~kJ} \mathrm{~mol}^{-1}$ ) than the triplet state; the simultaneous presence of the singlet dianions of $\mathbf{3}$ and $\mathbf{5}$ in the solutions is compatible with evidence from NMR spectroscopy. An even more prolonged contact with potassium metal leads to radical trianions with the unpaired electron accommodated in the central phane unit. These radical trianions can thus be regarded as the radical anions of [2.2]paracyclophane having two negatively charged lateral $\pi$-systems attached to it. Detection of trianions in a quartet state by ESR spectroscopy proved to be difficult under the experimental conditions used. The sequential uptake of three electrons by 3-5 is discussed in the light of the reduction potentials of the constituent $\pi$-systems.
\end{abstract}

Replacement of the ethano bridging groups in [2.2]paracyclophane (1) by $o$-phenylenes leads to the dibenzo derivative 2. The $D_{2 h}$ symmetry of 1 is preserved in 2 , as the planes of the lateral benzene rings are perpendicular to the mean planes of the benzene decks in the central phane unit. ${ }^{2}$ The first synthesis of 2 was reported a few years ago. ${ }^{3}$ More recently, not only 2 but also its derivatives 3,4 , and 5 , bearing phenyl substituents at the lateral rings, have become readily available via a simple preparative route. $^{4}$

\footnotetext{
To whom correspondence should be addressed.

Universităt Hamburg.

Universität Basel.

I Present address: Institut für Organische Chemie der Universität Göttingen, Tammannstrasse 2, D-3400 Göttingen, F.R.G.
}

Reaction of 2 with potassium or cesium mirror in an ethereal solvent yielded a fairly persistent radical anion $2^{\circ-}$, which has been studied in detail by ESR, ENDOR, and TRIPLE-resonance spectroscopy. ${ }^{5}$ The unpaired electron in $2^{\circ-}$ is accommodated

(1) Presented, in part, at the 5th International Symposium on Organic Free Radicals, Zürich, Switzerland, September 1988.

(2) Wong, H. N. C.; Chan, C. W.; Mak, T. C. W. Acta Crystallogr. 1986, C42, 703 .

(3) Chan, C. W.; Wong, H. N. C. J. Am. Chem. Soc. 1985, 107, 4790.

(4) (a) Stöbbe, M.; Reiser, O.; Näder, R.; de Meijere, A. Chem. Ber. 1987 120,1667. (b) Reiser, O.; Reichow, S.; de Meijere, A. Angew. Chem. 1987 99, 1285; Angew. Chem., Int. Ed. Engl. 1987, 26, 1277. (c) Reiser, O. Dissertation, Hamburg, 1989. (d) Reiser, O.; Khan, S. I,; de Meijere, A., manuscript in preparation.

(5) Gerson, F.; Martin, W. B., Jr.; Wong, H. N. C.; Chan, C. W. Helv. Chim. Acta 1987, 70, 79 


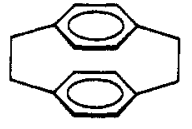

1

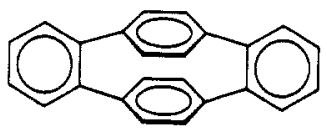

2<smiles>[R]c1ccc(-c2ccc3c(c2)-c2ccc(cc2)-c2ccc(-c4ccc([R])cc4)cc2-3)cc1</smiles>

$3 \mathrm{R}=\mathrm{H}$

$3-d_{2} \quad R=D$<smiles>c1ccc(-c2ccc(-c3ccc4c5cc(-c6ccccc6)ccc5c5ccccc5c4c3)c(-c3ccccc3)c2)cc1</smiles>

4

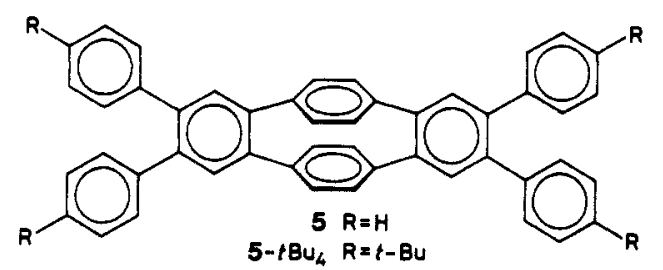

mainly in the central phane unit, in accord with the reduction potential, $E_{1 / 2}{ }^{(1)}$, of $1(-3.00 \mathrm{~V} \text { vs } S C E)^{6,7}$ being substantially less negative than that of benzene $(-3.42 \mathrm{~V}){ }^{7,8}$ Actually, the $E_{1 / 2}{ }^{(1)}$ value of 2 is $-2.68 \mathrm{~V},{ }^{9 a}$ as the uptake of an electron by the central phane unit becomes easier by the enlargement of the molecular framework on passing from 1 to 2. Also, due to the presence of several mutually orthogonal $\pi$-systems, 2 can accept more than one electron," but its dianion proved not persistent enough to allow detection by ESR or NMR spectroscopy. Prolonged reduction of 2 with an alkali metal in ethereal solvents at low temperatures resulted in the formation of secondary products, which arose from the cleavage of a bond between benzene rings. ${ }^{10}$

The propensity of a molecule to take up electrons and the persistence of multiply charged anions are usually enhanced by greater delocalization of the negative charges. In the case of 2 , such an enhancement should thus be brought about through phenyl substitution of the lateral benzene rings by which the $\pi$-systems of these rings in 2 are extended to those of biphenyl in 3 and 4 and of 0 -terphenyl in 5 . One may, therefore, expect that further reduction of the radical anions $3^{0-}-5^{+-}$will yield multiply charged species that are sufficiently persistent to be characterized by ESR or NMR spectroscopy. As is shown in the present paper, this expectation has been fully borne out by experiment, which also determines how the phenyl substitution of the lateral benzene rings, on going from 2 to $3-5$, influences the distribution of the uptaken electrons in the anions.

\section{Results and Discussion}

Radical Anions. Reaction of the phenyl-substituted dibenzo[2.2] paracyclophanes 3, 3- $d_{2}, 4,5$, and 5- $t \mathrm{Bu}_{4}$ with potassium mirror generated the corresponding radical anions. 1,2-Dimethoxyethane (DME), tetrahydrofuran (THF), and 2-methyltetrahydrofuran (MTHF) served as solvents; in several samples hexamethylphosphoric acid triamide (HMPT) was added to DME.

(6) Jund, R.; Lemoine, P.; Gross, M. Angew. Chem. 1982, 94, 312; Angew. Chem. Int., Ed. Engl. 1982, 21, 305.

(7) See also: Gerson, F.; Ohya-Nishiguchi, H.; Wydler, C. Angew. Chem. 1976, 88, 617; Angew. Chem., Int. Ed. Engl. 1976, 15, 552.

(8) Mortensen, J.; Heinze, J. Angew. Chem. 1984, 96, 64; Angew. Chem., Int. Ed. Engl. 1984, 23, 84.

(9) Cyclic voltammetric studies by J. Heinze, Freiburg, F.R.G., unpublished data. (a) Solvent, DME/THF (1:1); temperature, $298 \mathrm{~K}$. (b) Solvent, $\mathrm{DME}$; temperature, $208 \mathrm{~K}$. Supporting salt, $\mathrm{Bu} 4 \mathrm{NBr}$.

(10) ${ }^{1} \mathrm{H}$ and ${ }^{13} \mathrm{C}$ NMR studies of the dianions and reoxidation experiments were carried out in the laboratories of M. Rabinovitz, Jerusalem, Israel, and K. Mallen, Mainz, F.R.G.

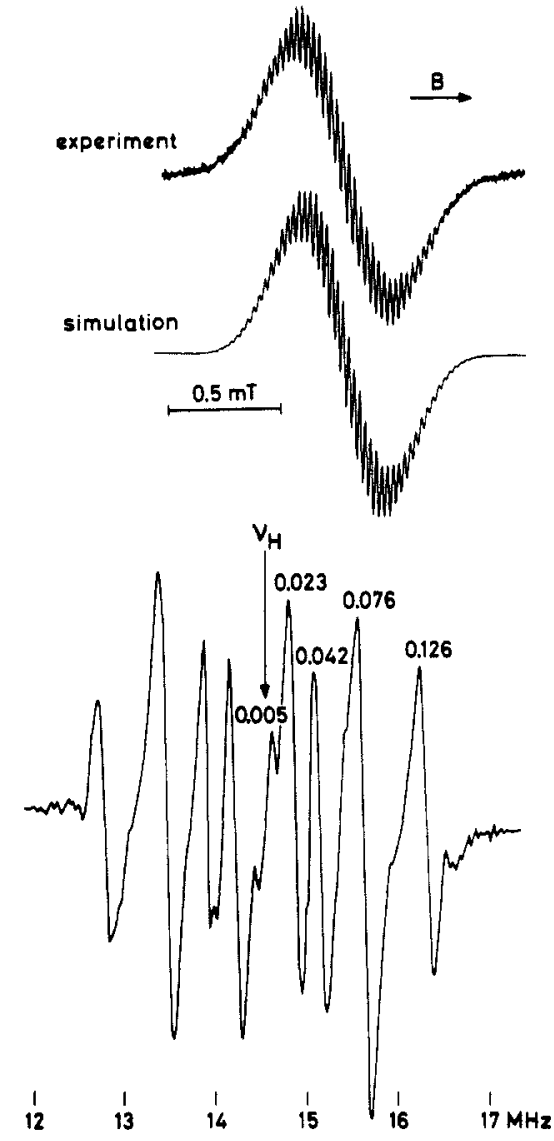

Figure 1. Top: ESR spectrum of the radical anion 5*-. Solvent, DME; temperature, $203 \mathrm{~K}$; counterion, $\mathrm{K}^{+}$. The simulation made use of the coupling constants given in Figure 2; line shape, Lorentzian; line width, $0.03 \mathrm{mT}$. Bottom: corresponding proton ENDOR spectrum. The numbers are the coupling constants (in $\mathrm{mT}$ ) associated with the signals.

The ESR spectra of the radical anions thus obtained were taken in the temperature range 193-263 K; they had a rather small total width $\left(1.4-1.5 \mathrm{mT}\right.$ for $3^{-}-5^{-} ; 1.1-1.2 \mathrm{mT}$ for $3-d_{2}^{-}$and $\left.5-t \mathrm{Bu}_{4}{ }^{-}\right)$. Their poor resolution was caused by a large number of protons having small coupling constants and, presumably, by electron exchange with simultaneously formed dianions. Analyses of these spectra were carried out by the ENDOR technique," as illustrated for $5^{\circ-}$ in Figure 1. The proton coupling constants for $3^{\circ-}, 4^{\circ-}$, and $5^{*-}$ are given in Figure 2. Their signs were determined by general TRIPLE resonance, " assuming that the largest values are negative. The coupling constants for $3^{\circ-}$ and $4^{\circ-}$ are almost half as large as those of the protons in the corresponding positions of the radical anion of biphenyl (6), 12 and they belong to sets of twice as many nuclei. Analogous relations hold for the proton coupling constants of $5^{-}$with respect to those of the radical anion of o-terphenyl (7). ${ }^{13}$ Assignments to protons in the individual positions of $3^{*--5^{-}}$have thus been based on comparison with the hyperfine data for $6^{\circ-}$ or $7^{-}$(Figure 2 ). These assignments were confirmed by ESR and ENDOR studies of $3-d_{2}{ }^{\circ-}$ and $5-t \mathrm{Bu}_{4}{ }^{\circ-}$. The changes observed on passing from $3^{\circ-}$ to $3-d_{2}{ }^{\circ-}$ and from $5^{\circ-}$ to $5-t \mathrm{Bu}_{4}{ }^{--}$were those expected for the replacement of the ring protons having the largest coupling constants $\left[3^{*-}, 0.212 \mathrm{mT}(2\right.$ $\mathrm{H}) ; 5^{\circ-}, 0.126 \mathrm{mT}(4 \mathrm{H})$ ] by deuterons and tert-butyl groups, respectively. Thus, a striking decrease $(0.3-0.4 \mathrm{mT})$ in the total width of the ESR spectra occurred, along with the disappearance

(11) See, e.g.: Kurreck, H.; Kirste, B.; Lubitz, W. Electron Nuclear Double Resonance Spectroscopy of Radicals in Solution; VCH Publishers: New York, 1988; Chapter 2.

(12) Wertz, J. E.; Bolton, J. R. Electron Spin Resonance: Elementary Theory and Practical Applications; McGraw-Hill: New York, 1972; 65.

(13) Proton coupling constants determined in this work; they are in essential agreement with those reported for $7^{\circ-}$ previously.14

(14) Plato, M.; Biehl, R.; Möbius, K.; Dinse, K. P. Z. Naturforsch. A 1976, $31,169$. 

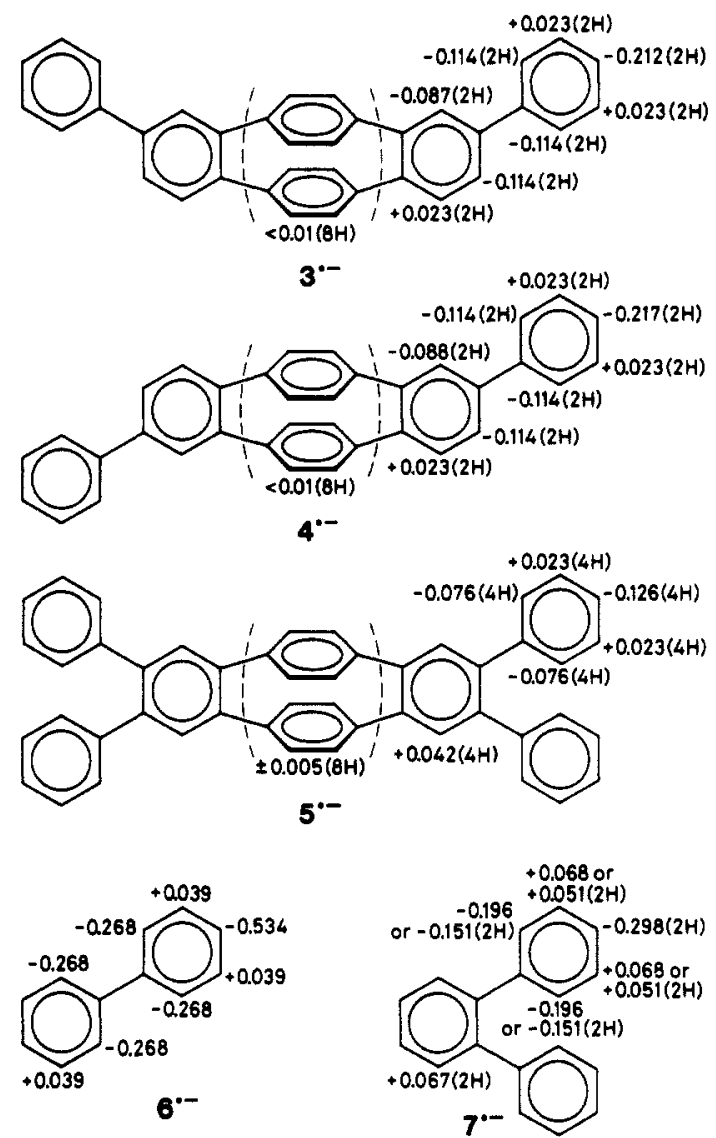

Figure 2. Coupling constants (in $\mathrm{mT}$ ) of the protons in the radical anions $3^{\circ-}, 4^{\circ-}$, and $5^{\circ-}$ and the corresponding values for $6^{\circ-}$ and $7^{\circ-}$. Experimental error, \pm 0.002 and $\pm 0.001 \mathrm{mT}$ for coupling constants (absolutely) larger and smaller than $0.1 \mathrm{mT}$, respectively. $g$ factor of $3^{+-5 *}, 2.0026$ \pm 0.0001 .

of the outermost proton ENDOR signals associated with the pertinent coupling constants. For the protons other than those in deuteriated or substituted positions, the coupling constants remained practically unchanged, as deduced from the ENDOR spectra. The hyperfine splitting from the two deuterons in $3-d_{2}{ }^{\circ-}$ was determined as $0.031 \mathrm{mT}$ from the deuteron ENDOR signals; that from the 36 protons of the four tert-butyl substituents in 5- $t \mathrm{Bu}_{4}{ }^{--}$could not be exactly measured by either ESR or ENDOR spectroscopy (it was estimated to be smaller than $0.005 \mathrm{mT}$ ).

The coupling constants for $3^{\circ-}-5^{\circ-}$ (Figure 2 ) depended only slightly on the solvent (DME, THF, MTHF, or DME/HMPT) and temperature (193-263 K). They clearly point out that, in contrast to $2^{\circ-}$, the unpaired electron in $3^{\circ-}-5^{\circ-}$ is taken up by one of the lateral $\pi$-systems and not by the central phane unit. The first reduction potentials, $E_{1 / 2}{ }^{(1)}$, of $6(-2.68 \mathrm{~V})^{15}$ and $7(-2.62$ $V)^{9 \mathrm{~b}}$ are considerably less negative than that of the parent cyclophane $1(-3.00 \mathrm{~V})$. Moreover, these potentials are equal to or slightly less negative than the $E_{1 / 2}{ }^{(1)}$ value of the dibenzocyclophane $2(-2.68 \mathrm{~V})$, which may here be regarded as a more appropriate reference compound than 1 . The finding that the unpaired electron prefers a $\pi$-system lateral to the central cyclophane unit in $3^{\circ-}-5^{--}$is thus, at least, not at variance with the first reduction potentials of the constituent systems in these molecules.

The hyperfine data for $3^{+-}-5^{--}$also indicate that, with some exceptions (see below), electron transfer between the two equivalent lateral $\pi$-systems is fast on the hyperfine time scale (ca. $10^{7}$ $\mathrm{Hz}$ ), and the unpaired electron appears to be delocalized over both systems. As the frequency of such an electron transfer is determined by the rate of synchronous migration of the counterion between its sites at the two moieties, the cation $\mathrm{K}^{+}$must move relatively fast from one lateral $\pi$-system to another, i.e., its as-

(15) Meerholz, K.; Heinze, J. J. Am. Chem. Soc. 1989, 111, 2325.
Table I. Zero-Field Splittings, $D^{\prime}$, and Mean Separation, $\bar{r}$, of the

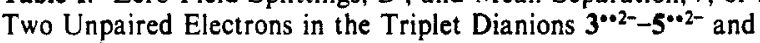
5- $t \mathrm{Bu}_{4} \cdot{ }^{\circ-2}$

\begin{tabular}{|c|c|c|c|c|}
\hline dianion & solvent temp, $\mathrm{K}$ & $D^{\prime a}{ }^{a} \mathrm{mT}$ & $\bar{r}, \mathrm{pm}$ & $r_{\mathrm{c}}{ }^{b} \mathrm{pm}$ \\
\hline \multirow[t]{2}{*}{$\overline{3 \times 2-}$} & THF 150 & 3.45 & 930 & 1160 \\
\hline & MTHF 115 & 3.65 & 915 & \\
\hline \multirow[t]{2}{*}{$4^{\cdot * 2-}$} & THF 150 & 2.70 & 1010 & 1180 \\
\hline & MTHF 115 & 3.05 & 970 & \\
\hline \multirow[t]{2}{*}{$5 \cdot 5^{\circ-}$} & THF 150 & 2.85 & 990 & 1270 \\
\hline & MTHF 115 & 3.35 & 940 & \\
\hline \multirow[t]{2}{*}{ 5- $t \mathrm{Bu}_{4} \cdot \cdot 2-$} & THF 150 & 3.35 & 940 & 1270 \\
\hline & MTHF 115 & 3.75 & 905 & \\
\hline
\end{tabular}

${ }^{a}$ Experimental error, $\pm 0.05 \mathrm{mT}$. ${ }^{b}$ Distance between the centers of the two lateral $\pi$-systems as derived from molecular models.

sociation with the radical anion is rather weak (loose ion pairs). The association becomes stronger when the cation solvating power of the solvent decreases, which is the case in the sequence DME/HMPT $>$ DME $>$ THF $>$ MTHF and also upon raising the temperature. Accordingly, proton ENDOR spectra of $5^{\circ}$ in THF and MTHF above $243 \mathrm{~K}$ exhibited additional weak signals corresponding to coupling constants exactly twice as large as those given in Figure 2. These signals are diagnostic of the electron transfer and the $\mathrm{K}^{+}$migration being slow on the hyperfine time scale and they arise from radical anions more strongly associated with the counterion (tight ion pairs). Thus, in THF or MTHF above $243 \mathrm{~K}$, loose and tight ion pairs of $5^{--}$with $\mathrm{K}^{+}$coexist in the same solution. Ample evidence of such a coexistence has accumulated in the last decade, particularly for the radical anions of cyclophanes. ${ }^{5,16}$

It is noteworthy that the protons in the "inner" and "outer" positions of the phenyl substituents in $5^{\circ}$ appeared to be equivalent even when, in this special case, the temperature was lowered from 193 to $158 \mathrm{~K}$ (solvent THF). From the width of the ENDOR signals (Figure 1), one estimates that the differences in the coupling constants of the "inner" and "outer" protons can be at most 0.012 and $0.005 \mathrm{mT}$ for the ortho and meta positions, respectively (Figure 2 ). Since the coalescence temperature must be lower than $158 \mathrm{~K}$, the upper limit to the free activation energy, $\Delta G^{*}$, for the rotation of the phenyl substituent was estimated as $21 \mathrm{~kJ} \mathrm{~mol}^{-1} .^{17}$ For the radical anion of 0 -terphenyl (7), the corresponding differences in the coupling constants are 0.045 and $0.017 \mathrm{mT}$ (Figure 2) and the pertinent energy is $29 \mathrm{~kJ} \mathrm{~mol}^{-1}$. $^{14}$ The lower $\Delta G^{\neq}$value for $5^{5^{-}}$compared to that for $7^{*-}$ is consistent with the $\pi$-bond order of the relevant inter-ring linkages; on going from 7 to $7^{+-}$, this order increases by 0.084 , but the analogous enhancement is only half as large on passing from 5 to $5^{\circ-}$ (delocalization of the unpaired electron over two lateral $o$-terphenyl $\pi$-systems).

Triplet Dianions. Upon prolonged contact of the solutions with the potassium mirror, the ESR spectra of the radical anions became less intense. At this stage, glassy solutions in frozen MTHF exhibited ESR signals characteristic of the triplet state. Interestingly, such triplet spectra could also be observed with THF as solvent yet slightly above its freezing point, as fully solidified THF does not form a glass. The triplet state is ascribed to the dianions $3^{\bullet \cdot 2-}, 3-d_{2} \cdot{ }^{\bullet 2-}, 4^{\bullet \cdot 2-}, 5^{\bullet \cdot 2-}$, and $5-t \mathrm{Bu}_{4}{ }^{\bullet 2-}$, which result from the uptake of an additional electron by the corresponding radical anions. The ESR spectra of these triplet dianions are exemplified in Figure 3 by that of $5^{\circ \cdot 2-}$ in viscous THF and those of $5^{\cdot 0^{2-}}$ and $5-t \mathrm{Bu}_{4}{ }^{\cdot 2-}$ in glassy MTHF. They apparently consist of two pairs of signals, because the $x$ and $y$ features almost coincide

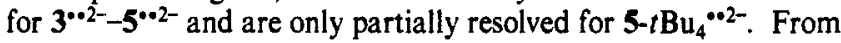
the spacing $2 D^{\prime}$ of the $z$ features, estimates for the mean distances $\bar{r}$ of the two unpaired electrons were obtained by the use of relation 18,19

$$
\bar{r}=3 \sqrt{2.78 \times 10^{9} / D^{\prime}}
$$

(16) Gerson, F. Top Curr. Chem. 1983, 115, 57.

(17) Günther, H. NMR Spektroskopie, 2nd ed.; Thieme-Verlag: Stuttgart, New York, 1983; p 229, eq 8.12. 

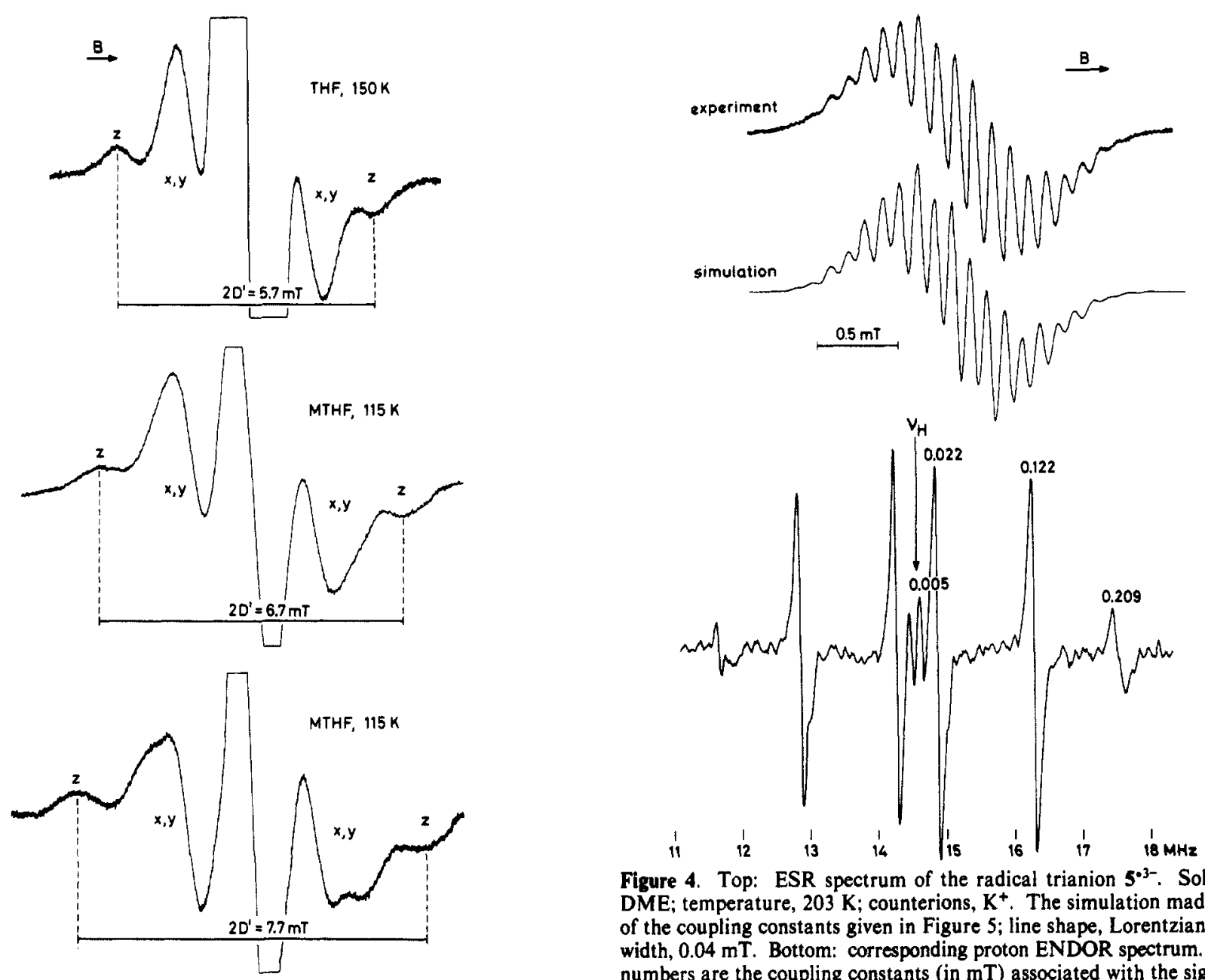

Figure 4. Top: ESR spectrum of the radical trianion $5^{* 3-}$. Solvent, DME; temperature, $203 \mathrm{~K}$; counterions, $\mathrm{K}^{+}$. The simulation made use of the coupling constants given in Figure 5; line shape, Lorentzian; line width, $0.04 \mathrm{mT}$. Bottom: corresponding proton ENDOR spectrum. The numbers are the coupling constants (in $\mathrm{mT}$ ) associated with the signals.

Figure 3. ESR spectra of the triplet dianions $5^{\circ * 2-}$ (top and center) and $5-t \mathrm{Bu}_{4}{ }^{\circ 2-}$ (bottom). Solvent and temperature as indicated. Counterions, $\mathrm{K}^{+}$.

where $\bar{r}$ is in picometers and $D^{\prime}$ in milliteslas. Table 1 gives the $2 D^{\prime}$ and $\bar{r}$ values for all triplet dianions, both in viscous THF and glassy MTHF. These values compare well with the distances, $r_{\mathrm{c}}$, between the centers of the two lateral biphenyl or 0 -terphenyl $\pi$-systems in 3-5. Thus, each of these lateral $\pi$-systems in $3^{* 2-}-5 \cdot 2-$ must accommodate one unpaired electron.

The relatively large separation (ca. $1 \mathrm{~nm}$ ) of the two electrons must here be responsible for the failure to observe the "forbidden" $\Delta M_{\mathrm{S}}=2$ transitions at the half-field ${ }^{19}$ For the same reason, the interaction between the two electrons should be slight, as should be the difference in the energies of the dianion singlet and triplet states (singlet-triplet splitting $2 J$ ). In fact, exhaustive reduction of 3 and 5 with $\mathrm{Li}, \mathrm{Na}$, or $\mathrm{K}$ in THF- $d_{8}$ at $195 \mathrm{~K}$ yielded ' $\mathrm{H}$ and ${ }^{13} \mathrm{C}$ NMR spectra that were ascribed to the singlet dianions $3^{2-}$ and $5^{2-}$, as reoxidation of the solutions regenerated the corresponding neutral compounds with an intact carbon framework. ${ }^{10}$ Reliable analyses of these spectra were, however, impaired by the low intensities of the signals and their large width caused by the presence of paramagnetic species. Studies of the temperature dependence performed on the ESR spectra of $5^{* 02-}$ in glassy MTHF suggest that the ground state of the dianions is triplet $(J$ $<0$ ). The intensities of these spectra increased steadily by lowering the temperature in the range $150-100 \mathrm{~K}$, relative to those of the corresponding radical anions taken at the same temperature prior to the formation of the dianions. The $J$ value estimated from these studies by applying the relation ${ }^{20}$

$$
\ln [I(t) / I(\mathrm{~m})]=-\ln [3+\exp (J / k T)]+\text { const }
$$

(18) Luckhurst, G. R. In Spin Labelling: Theory and Applications; Berliner L. J., Ed.; Academic Press: New York, 1976, Chapter 4.

(19) See, e.g.: Eaton, S. S.; More, K. M.; Sawant, B. M.; Eaton, G. R. J. Am. Chem. Soc. 1983, 105, 6560 .

is $-2 \mathrm{~kJ} \mathrm{~mol}^{-1}$ where $I(\mathrm{t})$ stands for the spectral intensity of the triplet dianion and $I(\mathrm{~m})$ for that of the radical monoanion.

Observation of singlet and triplet dianions for the same hydrocarbon is not unprecedented. It has been reported ${ }^{21}$ that such diamagnetic and paramagnetic species were produced by reaction of 1,2-di(9-anthryl)ethane with alkali metals in an ethereal solvent and that they have been characterized by their NMR and ESR spectra, respectively. The ${ }^{1} \mathrm{H}$ and ${ }^{13} \mathrm{C}$ NMR spectra of the singlet dianions pointed to an even distribution of the two negative charges over both anthracene $\pi$-systems of the hydrocarbon. ${ }^{21}$

Radical Trianions. In all triplet ESR spectra, strong central absorption was observed. Its intensity increased on further contact with the potassium mirror at the expense of the triplet-state signals. In fluid solutions, this absorption gave rise to well-defined ESR and ENDOR spectra, which drastically differed from those of the corresponding radical anions. Their total width was ca. 2.5 $\mathrm{mT}$, i.e., almost twice as much as that observed for $3^{\circ-}-5^{\circ-}$. The new paramagnetic species were identified as the radical trianions $3^{\circ 3-}, 3-d_{2}{ }^{\cdot 3-}, 4^{\cdot 3-}, 5^{\cdot 3-}$, and 5- $t \mathrm{Bu}_{4}{ }^{\cdot 3-}$, formed from the dianions by the uptake of a third additional electron. This attribution was corroborated by the finding that photooxidation of the solutions with a high-pressure $\mathrm{Hg}$ lamp $(\lambda>330 \mathrm{~nm}$, cut off by a Pyrex filter) led to a partial reappearance of the ESR spectra of the respective radical anions. ${ }^{22}$

The ESR and ENDOR spectra of the radical trianions, taken at 193-263 K with DME, THF, and MTHF as solvents, are illustrated in Figure 4 by those of $5^{\cdot 3-}$. Since the ESR resolution

(20) Broser, W.; Siegle, P.; Kurreck, H. Chem. Ber. 1967, 100, 788. Scheffler, K.; Stegmann, H. B. Elektronenspinresonanz: Grundlagen und Anwendungen in der Organischen Chemie; Springer-Verlag: Berlin, Heidelberg, New York, 1970; 233.

(21) Huber, W.: Unterberg, H.; Müllen, K. Angew. Chem. 1983, 95, 239; Angew. Chem., Int. Ed. Engl. 1983, 22, 242.

(22) Gerson, F.; Huber, W. Acc. Chem. Res. 1987, 20, 85. 


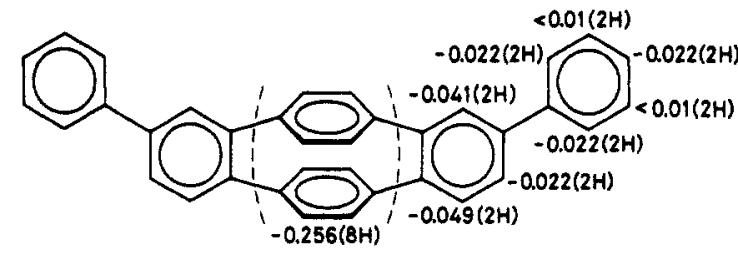

$3^{\cdot 3-}$

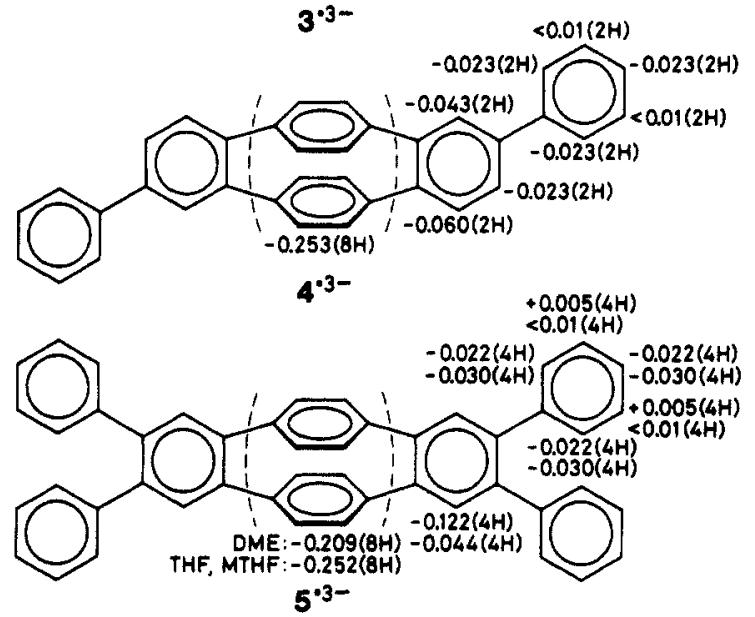

$5^{\cdot 3-}$

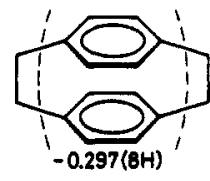

$1^{\cdot-}$

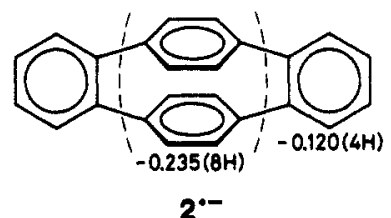

Figure 5. Coupling constants (in $\mathrm{mT}$ ) of the protons in the radical trianions $3^{\cdot 3-}, 4^{3-}$, and $5^{\cdot 3-}$ and the corresponding values for the radical anions $1^{-}$and $2^{\circ-}$. In the case of $5^{\circ-}$, the upper numbers refer to DME, and the lower ones to THF and MTHF as solvent. Experimental error, \pm 0.002 and \pm 0.001 for the coupling constants (absolutely) larger and smaller than $0.1 \mathrm{mT}$, respectively. $g$ factor of $3^{\cdot 3-}-5^{\cdot 3-}, 2.0026 \pm 0.0001$

was incomplete, the proton coupling constants again had to be derived from the ENDOR spectra. They are given for $3^{\cdot 3-}, 4^{\cdot 3-}$, and $5^{\mathbf{3}^{2}}$ in Figure 5, along with the analogous values for the radical anions of the cyclophanes 1 and 2.,16 Assignments of the by far largest coupling constant to the eight protons in the central phane unit of $3^{\cdot 3-}-5^{\cdot 3-}$ have been based on their similarity to the corresponding values for $1^{--}$and $2^{*-}$. Assuming these coupling constants to be negative, the signs of the remaining ones were determined by general TRIPLE resonance." The hardly noticeable changes in the ESR and ENDOR spectra caused by deuteriation $\left(3^{\cdot 3-} \rightarrow 3-d_{2}{ }^{3-}\right)$ or tert-butyl substitution $\left(5^{\cdot 3-} \rightarrow\right.$ 5- $\left.t \mathrm{Bu}_{4}{ }^{\cdot 3-}\right)$ in the phenyl para positions are in accord with the protons in these positions having only minor coupling constants. As is evident from Figure 5, the values for $5^{.3-}$ in DME differed from those observed with THF and MTHF as solvents; the latter resembled the coupling constants for $3^{\cdot 3-}$ and $4^{\cdot 3-}$, which were practically identical with all three solvents used.

The hyperfine data point unequivocally at the accommodation of the unpaired electron in $3^{\cdot 3-}-5^{\cdot 3-}$ by the central phane unit. Thus, these radical trianions can be regarded as the radical anion of [2.2] paracyclophane (1), which is flanked by two lateral $\pi$ systems orthogonal to it, each bearing one negative charge.

Starting with the dianions, an additional electron may, in principle, be accepted either by one of these singly charged $\pi$ systems or by the formally uncharged central phane unit. Relevant in this respect are the second reduction potentials, $E_{1 / 2}{ }^{(2)}$, of the lateral $\pi$-systems, biphenyl (6) or 0 -terphenyl (7), as compared with the first reduction potentials, $E_{1 / 2}{ }^{(1)}$, of the cyclophanes 1 and 2 . In the case of $3^{\cdot 3-}$ and $4^{\cdot 3-}$, the preference of the unpaired electron for the central phane unit can readily be accounted for by the $E_{1 / 2}{ }^{(2)}$ value of $-3.18 \mathrm{~V}$ for $6^{15}$, which is significantly more negative than the potentials $E_{1 / 2}{ }^{(1)}$ of both $1(-3.00 \mathrm{~V})$ and 2 $(-2.68 \mathrm{~V})$. This preference is less straightforward in the case of

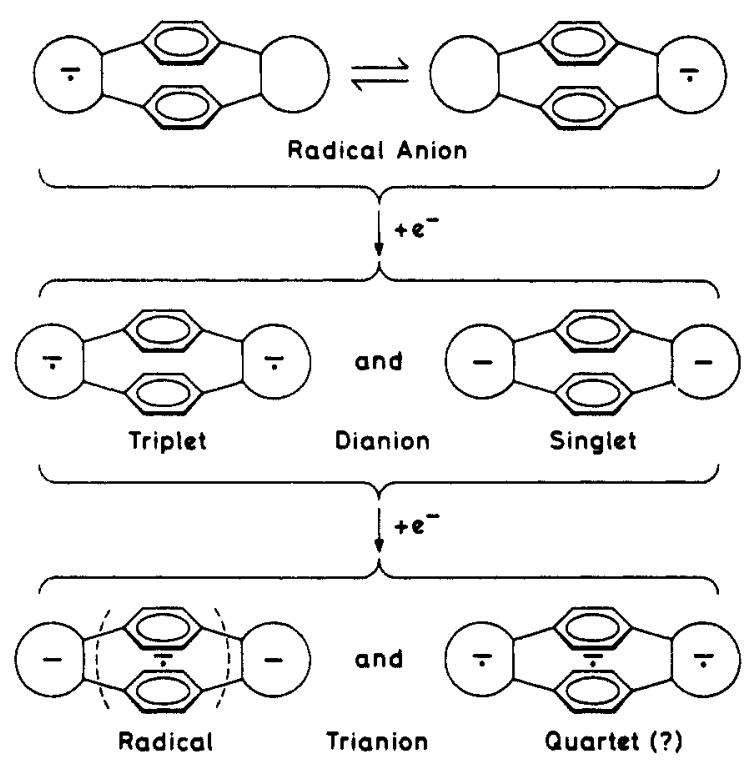

Figure 6. Schematic representation of the mono-, di-, and trianions obtained upon the consecutive uptake of three electrons by 3-5. The (incomplete) circles stand for the lateral biphenyl or 0 -terphenyl $\pi$-systems. Paired and unpaired electrons are symbolized by a minus sign ( - ) and a minus sign above a dot ( $\left.{ }^{\circ}\right)$, respectively. ${ }^{27}$

$5^{\circ 3-}$, as the $E_{1 / 2}{ }^{(2)}$ value of 7 is $-2.72 \mathrm{~V}^{9 b}$ and thus only slightly more negative than $-2.68 \mathrm{~V}$. Nevertheless, the hyperfine data for $5^{.3-}$ leave no doubt that in this radical trianion the unpaired electron is also mainly located in the central phane unit and not in a lateral 0 -terphenyl $\pi$-system. Association of the radical trianion with three $\mathrm{K}^{+}$counterions can play an important role in this case. It manifests itself for $5^{\mathbf{6}^{3-}}$ by the striking dependence of the coupling constants on the solvent (Figure 5), a behavior contrasting that of $3^{\cdot 3-}$ and $\mathbf{4}^{\circ 3-}$.

Under the experimental conditions used in these studies (solvent, DME, THF, or MTHF; temperature, 193-263 K), the eight cyclophane protons throughout appeared to be equivalent $\left(5^{\circ-}\right)$ or practically equivalent $\left(3^{\cdot 3-}\right.$ and $\left.4^{* 3-}\right)$. This finding indicates that $\mathrm{K}^{+}$migration and electron transfer between the two cyclophane benzene decks must be fast on the hyperfine time scale. ${ }^{16}$

Formation of the trianions by 3-5 might also lead to a quartet state in which three electrons are unpaired. A number of reports on paramagnetic molecules in a quartet ground state exist in the literature..$^{23-26}$ All these species are neutral triradicals containing three identical monoradical moieties such as triarylmethyl, ${ }^{23}$ verdazyl, ${ }^{24}$ hydrazyl, ${ }^{25}$ and aroxyl ${ }^{26}$ (in particular, galvinoxyl ${ }^{260-d}$ ). To our knowledge, quartet trianions of $\pi$-systems, like those in 3-5, have not yet been studied. For a quartet molecule in a glassy solution, one expects that the ESR spectrum should consist of five signals when $x$ and $y$ features coincide. ${ }^{23 b-d, 24 a, b, 25,26 a, c}$ Characteristic of this spectrum is the appearance of a strong absorption

(23) (a) Schmauss, G.: Baumgärtel, H.; Zimmermann, H. Angew. Chem. 1965, 77, 619; Angew. Chem., Int. Ed. Engl. 1965, 4, 596. (b) Kothe, G.; Ohmes, E.; Brickmann, J.; Zimmermann, H. Angew. Chem. 1971, 83, 1015 ; Angew. Chem., Int. Ed. Engl. 1971, 10,938. (c) Reibisch, K.; Kothe, G.; Brickmann, J. Chem. Phys. Lett. 1972, 17, 86. (d) Kothe, G.; Brickmann, J. J. Chem. Phys. 1973, 59, 2807.

(24) (a) Kothe, G.; Neugebauer, F. A.; Zimmermann, H. Angew. Chem. 1972, 84, 890; Angew. Chem., Int. Ed. Engl. 1972, 11, 830. (b) Kothe, G.; Ohmes, E. Ber. Bunsenges. Phys. Chem. 1974, 78, 924. (c) Kothe, G.; Naujok, A.: Ohmes, E. Mol. Phys. 1976, 32, 1215. (d) Kothe, G. Mol, Phys. 1977, 33, 147. (e) Kothe, G.; Ohmes, E. J. Mol. Struct. 1978, 46, 481. (f) Kothe, G.; Berthold, T.; Ohmes, E. Mol Phys. 1980, 40, 1441.

(25) (a) Weissman, S. I.; Kothe, G. J. Am. Chem. Soc. 1975, 97, 2537. (b) Kothe, G.; Wassmer, K. H.; Naujok, A.; Ohmes, E.; Rieser, J.; Wallenfels K. J. Magn. Reson. 1979, 36, 425

(26) (a) Nowak, C.: Kothe, G.; Zimmermann, H. Ber. Bunsenges. Phys. Chem 1974, 78, 265. (b) Harrer, W.; Kurreck, H.; Reusch, J.; Gierke, W. Tetrahedron 1975, 31, 625. (c) Kirste, B.; van Willigen, H.; Kurreck, H.; Möbius, K.; Plato, M.; Biehl, R. J. Am. Chem. Soc. 1978, 100, 7505. (d) Schubert, K.; Kirste, B.; Kurreck, H. Angew. Chem. 1983, 95, 149; Angew. Chem., Int. Ed. Engl. 1983, 22, 150. 
$(x, y, z)$ at the center, apart from the outer pair of signals $(z)$, separated by $4 D^{\prime}$ and the inner pair $(x, y)$ spaced by $2 D^{\prime}$. Evidently, in the case of 3-5, such an absorption would be masked by that of the doublet trianions $3^{\cdot 3-}-5^{\cdot 3-}$. Thus, prospects to detect the corresponding quartet trianions of 3-5 are rather dim.

\section{Conclusions}

The subsequent reduction steps leading to paramagnetic monodi-, and trianions are schematically depicted for 3-5 in Figure 6. These species have been characterized as follows:

(i) Radical (doublet) anions, $3^{\circ-}-5^{\circ-}$, with one unpaired electron in a lateral $\pi$-system. Electron exchange with the second equivalent system is fast on the hyperfine time scale, except under conditions of tight ion pairing.

(ii) Triplet dianions, $3^{\cdot * 2-}-5^{* \bullet 2-}$, with two unpaired electrons, one in each of the two lateral $\pi$-systems. Experimental evidence suggests a simultaneous presence of singlet dianions in which the two electrons are paired. ${ }^{27}$

(iii) Radical (doublet) trianions, $3^{\cdot 3^{3}-}-5^{\cdot 3-}$, with two paired electrons, in each of the lateral $\pi$-systems and one unpaired electron in the central phane unit. Simultaneous occurrence of quartet trianions, with three unpaired electrons, could not be confirmed experimentally.

This interpretation is in full accord with the cyclic voltammogram of $5-t \mathrm{Bu}_{4} .^{9 \mathrm{a}}$ The first two reversible reduction waves of this compound appear at $E_{1 / 2}(1)=-2.54 \mathrm{~V}$ (neutral $\stackrel{+e^{-}}{\longrightarrow}$ monoanion) and $E_{1 / 2}{ }^{(2)}=-2.61 \mathrm{~V}$ (monoanion $\stackrel{+\mathrm{e}^{-}}{\longrightarrow}$ dianion), i.e. close to the potential $E_{1 / 2}{ }^{(1)}$ of the terphenyl $7(-2.62 \mathrm{~V})$, whereas a third, likewise reversible, wave is observed at $E_{1 / 2}^{(3)}=-2.80$

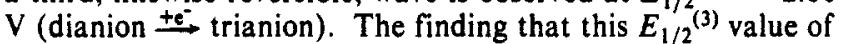
5- $t \mathrm{Bu}_{4}$ is somewhat more negative than the potential $E_{1 / 2}{ }^{(1)}$ of the dibenzocyclophane $2(-2.68 \mathrm{~V})$ can readily be rationalized in terms of the two negative charges that are present in the lateral $\pi$-systems of 5-t $\mathrm{Bu}_{4}$ at the uptake of an additional electron by the central phane unit (Figure 6).

(27) Due to an excessive line broadening, the NMR spectra of the singlet dianions could not be reliably analyzed (see above), so that the charge distribution in these diamagnetic species has not been established unequivocally. As indicated in Figure 6, it is assumed that each of the two lateral $\pi$-systems accommodates one negative charge. Such a structure is considered to be favored by electrostatic repulsion and it also complies with the spin distributions in the corresponding radical anions and, particularly, in the radical trianions. However, an alternative structure with both electrons occupying, at least temporarily, only one of the lateral $\pi$-systems cannot be completely ruled out in default of direct experimental evidence.

\section{Experimental Section}

The syntheses of $3,{ }^{4 a, c} 4,4, c 5, b$ and $5-t \mathrm{Bu}_{4}{ }^{4 c}$ have been reported; a detailed description will be given in a forthcoming paper. ${ }^{4 d}$ 3- $d_{2}$ was prepared by a procedure analogous to that used for $33^{4 a, c}$ with the reagent styrene being replaced by its $p$-deuterio derivative.

p-Deuteriostyrene. A $2.2 \mathrm{M}$ solution of $n$-butyllithium $(22 \mathrm{~mL}, 48.4$ $\mathrm{mmol}$ ) in $n$-hexane was added at $-108^{\circ} \mathrm{C}$ to a solution of $p$-bromostyrene $(8.0 \mathrm{~g}, 43.5 \mathrm{mmol})$ in a mixture of THF, diethyl ether, and $n$-hexane $(60$ $\mathrm{mL}, 4: 1: 1)$. After $5 \mathrm{~min}$, deuterium oxide $(2 \mathrm{~mL}, 100 \mathrm{mmol})$ was admitted; the reaction mixture was warmed to room temperature and, following an addition of ice-water $(50 \mathrm{~mL})$, it was diluted with diethyl ether $(200 \mathrm{~mL})$. The organic layer was washed with a saturated solution of ammonium chloride $(2 \times 100 \mathrm{~mL})$ and water and dried over magnesium sulfate. The solvent was evaporated and the residue distilled, yielding $3.66 \mathrm{~g}(80 \%)$ of $p$-deuteriostyrene: bp $72{ }^{\circ} \mathrm{C}(100 \mathrm{mmHg}) ;{ }^{1} \mathrm{H}$ NMR $\delta 5.23$ (dd, ${ }^{2} J=1.1 \mathrm{~Hz},{ }^{3} J_{\text {cis }}=11 \mathrm{~Hz}, 1 \mathrm{H}, \mathrm{H}-2^{\prime}$ cis), 5.75 (dd, ${ }^{3} J_{\text {trans }}=18 \mathrm{~Hz}, 1 \mathrm{H}, \mathrm{H}-2^{\prime}$ trans), 6.72 (dd, $1 \mathrm{H}, \mathrm{H}-1^{\prime}$ ), 7.32 and 7.42 (dd, $\left.{ }^{3} J=8 \mathrm{~Hz}, 4 \mathrm{H}, \mathrm{Ar}-\mathrm{H}\right) ; \mathrm{MS}, m / e$ (relative intensity) $105\left(\mathrm{M}^{+}, 100\right), 104$ (27), $79(17), 78(13)$

$4^{\prime}, 5^{\prime \prime}$-Bis(p-deuteriophenyl)dibenzo[2.2]paracyclophane-1,9-diene (3d 2). 1,9(10)-Dibromo[2.2] paracyclophane-1,9-diene $(1.0 \mathrm{~g}, 1.76 \mathrm{mmol}$ reacted with $1.5 \mathrm{~mL}(15.9 \mathrm{mmol})$ of p-deuteriostyrene to yield $800 \mathrm{mg}$ (71\%) of 1,9(10)-bis[2'-(E)-p-deuteriostyryl][2.2]paracyclophane-1,9diene ${ }^{4 a, c}$ Reaction of this compound $(800 \mathrm{mg}, 1.96 \mathrm{mmol})$ with propynal (400 mg, $7.4 \mathrm{mmol}$ ) afforded $220 \mathrm{mg}(22 \%)$ of $5^{\prime}, 5^{\prime \prime}$-bis(p-deuteriophenyl)dibenzo[2.2] paracyclophane-1,9-diene- $4^{\prime}, 4^{\prime \prime}$-dicarbaldehyde and $250 \mathrm{mg}(25 \%)$ of $4^{\prime \prime}, 5^{\prime}$-bis ( $p$-deuteriophenyl)dibenzo[2.2] paracyclophane-1,9-diene-4', $5^{\prime \prime}$-dicarbaldehyde. Decarbonylation of the latter gave $67 \mathrm{mg}(30 \%)$ of $3-d_{2}$ with a deuterium content in the two para positions better than $90 \%$ (according to ${ }^{1} \mathrm{H}$ NMR).

All paramagnetic species obtained by reduction with potassium in an ethereal solvent were persistent at temperatures below $263 \mathrm{~K}$

The ESR spectra were taken on a Varian-E9 instrument, while a Bruker ESP-300 system served for the ENDOR and TRIPLE-resonance studies.

Acknowledgment. We are greatly obliged to Prof. M. Rabinovitz, The Hebrew University of Jerusalem, Israel, and K. Müllen, Johannes Gutenberg-Universität Mainz, F.R.G., in whose laboratories the NMR studies of the reduction products of 2, 3, and 5 were carried out. Our thanks are also due to Prof. J. Heinze, University of Freiburg, F.R.G. for communicating his cyclic voltammetric data to us prior to publication. Financial support by the Swiss National Science Foundation and the German Fonds der Chemischen Industrie is greatfully acknowledged. B.K. and O.R. are indebted to the Studienstiftung des Deutschen Volkes for graduate fellowships.

\title{
Hydrogen-Deuterium-Exchange Reactions of Methoxide-Methanol Clusters
}

\author{
S. E. Barlow, Thuy Thanh Dang, and Veronica M. Bierbaum* \\ Contribution from the Department of Chemistry and Biochemistry, University of Colorado, \\ Boulder, Colorado 80309-0215. Received January 10, 1990
}

\begin{abstract}
The tandem flowing afterglow-selected ion flow tube has been employed to measure rate coefficients for a series of 12 bimolecular isotope-exchange reactions of methoxide-methanol clusters. From these kinetic measurements the dissociation energies of several hydrogen-bonded dimers were determined: $\mathrm{CH}_{3} \mathrm{O}^{-} \cdot \mathrm{DOCH}_{3}(28.3 \pm 0.1 \mathrm{kcal} / \mathrm{mol}), \mathrm{CH}_{3} \mathrm{O}^{-} \cdot \mathrm{HOCD}_{3}(28.5$ $\pm 0.1 \mathrm{kcal} / \mathrm{mol}), \mathrm{CH}_{3} \mathrm{O}^{-} \cdot \mathrm{DOCD}_{3}(28.1 \pm 0.1 \mathrm{kcal} / \mathrm{mol}) \mathrm{CD}_{3} \mathrm{O}^{-} \cdot \mathrm{HOCD}_{3}(28.9-0.1 \mathrm{kcal} / \mathrm{mol})$, and $\mathrm{CD}_{3} \mathrm{O}^{-} \cdot \mathrm{DOCD}_{3}(28.5$ $\pm 0.1 \mathrm{kcal} / \mathrm{mol}$ ). Differences in the bond strengths of these cluster ions can be understood in terms of the acidity of the neutral molecule and the basicity of the anion involved in the cluster; a given ion makes a stronger bond with a stronger acid while a given neutral molecule makes a stronger bond with a stronger base. By use of literature values of the electron affinity of the methoxy radicals along with the known RO-H and RO-D bond strengths, the gas-phase acidities $\left(\Delta H^{\circ}{ }_{\text {acid }}\right)$ of $\mathrm{CD}_{3} \mathrm{OD}$ $(383.9 \pm 0.7 \mathrm{kcal} / \mathrm{mol}), \mathrm{CH}_{3} \mathrm{OD}(383.5 \pm 0.7 \mathrm{kcal} / \mathrm{mol})$, and $\mathrm{CD}_{3} \mathrm{OH}(382.0 \pm 0.7 \mathrm{kcal} / \mathrm{mol})$ were calculated. A simple model is employed to predict reaction efficiencies and branching ratios for these isotope-exchange reactions.
\end{abstract}

\section{Introduction}

One of the goals of gas-phase ion chemistry is to determine intrinsic reactivities and thermochemistry in order to provide a fuller understanding of solution chemistry. A particularly powerful tool toward this end is to employ cluster ions and investigate the effects of solvation as solvent is added to a reaction, one molecule 